\title{
Interactions between sorbitol-type nucleator and additives for polypropylene
}

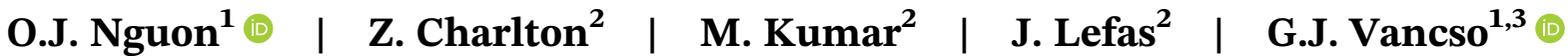

${ }^{1}$ Sulis Polymers B.V., Hengelo, The Netherlands

${ }^{2}$ Ingenia Polymers International S.A., Luxembourg

${ }^{3}$ Materials Science and Technology of Polymers, MESA+ Institute for Nanotechnology, University of Twente, Enschede, The Netherlands

\section{Correspondence}

G.J. Vancso, Materials Science and Technology of Polymers, MESA+ Institute for Nanotechnology, University of Twente, PO Box 217, 7500 AE, Enschede, The Netherlands.

Email: g.j.vancso@utwente.nl

\begin{abstract}
The thermal properties of a sorbitol-type nucleating agent (viz. 1,2,3-trideoxy4,6:5,7-bis-O-[(4-propylphenyl)methylene]-nonitol (TBPMN)) were examined in this study, and the influence of common processing additives assessed. In addition, we describe a novel approach to monitor in situ the self-assembly of the nucleator in presence of additives by optical microscopy. The performance of sorbitol compounds is closely associated to their chemical structure and ability to self-assemble. TBPMN formed elongated fibrils from the melt under inert atmosphere, in molted polypropylene, or in presence of antioxidants. However, calcium stearate (CaSt) and glycerol monostearate hampered growth, and yielded thinner fibrils. In presence of the additives, melting point depression of the nucleator occurred, and resulted in a lower degree of crystallinity upon cooling. Performance evaluation of the nucleator in polypropylene blends revealed an increased crystallization temperature when antioxidants were present, while CaSt inhibited nucleator activity. The effect of monoglycerides was found highly dependent on the processing conditions. Noteworthy, blends containing all the additives displayed the highest performance. This study highlights the importance of the preparation method of polymer additive blends to achieving the best performance in the final product. Characterization was performed by thermogravimetric analysis, Fourier-transform infrared spectroscopy, optical microscopy, and differential scanning calorimetry.
\end{abstract}

\section{K E Y W O R D S}

additives, clarifier, crystallization, nucleator, polypropylene, self-assembly, sorbitol

\section{1 | INTRODUCTION}

The versatile and attractive properties of polypropylene (PP) have established this polyolefin as one of the leading thermoplastic materials, with a global production reaching 56 million metric tons in $2018 .^{[1]}$ The combination of low density, excellent chemical and thermal resistance, good mechanical and optical properties, low cost, and versatile processing conditions has enabled a vast range of applications. ${ }^{[2]}$ The material properties are contingent on the semi-crystalline arrangement of the polymer chains. During processing, crystallization of the polymer can be tuned by addition of a nucleating agent. ${ }^{[3]}$ Such additives expose a heterogeneous surface that promotes nucleation, and yield the formation of small crystalline domains with a narrow size-distribution. 
In addition, increase of the crystallization temperature enables shorter cycle-times and energy efficiency. ${ }^{[4]}$

One important class of nucleating agents is dibenzylidene polyol (DBP)-based compounds, also referred to as sorbitol-type compounds. ${ }^{[5]}$ They find particular use as clarifying agents for PP materials. ${ }^{[6,7]}$ These compounds have been shown to dissolve in the polymer melt; and upon cooling, to self-assemble into a nanosized three-dimensional fibrillar network prior to crystallization of the polymer. ${ }^{[8,9]}$ The large exposed surface area promotes a high nucleation density and formation of small crystalline domains. Such a mechanism was shown particularly beneficial in imparting low haze and high transparency to PP materials. ${ }^{[10]}$ While sorbitol-type compounds display only a low solubility in PP, improved performance can be achieved by optimizing the concentration, processing conditions, and cooling rate. ${ }^{[11,12]}$ Among DBP-based compounds, 1,2,3-trideoxy4,6:5,7-bis-O-[(4-propylphenyl)methylene]-nonitol

(TBPMN) is the most recent commercial clarifier, providing improved optical transparency and organoleptics, reduced yellowing, greater solubility in $\mathrm{PP}$, and lower processing temperatures. ${ }^{[13,14]}$

In addition to nucleating agents, other additives are commonly employed as processing aids. Calcium stearate (CaSt) acts as an acid scavenger and an internal processing lubricant. ${ }^{[15,16]}$ In chromium and Ziegler-Natta catalyzed polypropylenes, the primary role of the metal stearate is to act as a neutralizer for catalyst residues. Its dissolution in the melt also facilitates polymer chain mobility and enhances melt flow. Fatty acid ethers, such as glycerol monostearate (GMS), act as antistatic additives and can display both internal and surface lubricating properties. ${ }^{[6,17]}$ Migration of the additive to the surface facilitates mold release, and further helps reducing plate out of sorbitol-type clarifiers. Antioxidants (AOs) are additives of primary importance for improving melt processing and long-term thermal stability. These compounds hinder the propagation of free-radicals formed during exposure to heat, shear, radiation, or from catalyst residues. Pentaerythritol tetrakis(3-[3,5-di-tert-butyl-4-hydroxyphenyl] propionate) (AO1010) is a hindered phenol primary antioxidant that reacts with free-radicals, and lowers their reactivity. Phosphite-based secondary AOs are used to reduce reactive hydroxyperoxides into more stable alcohols. Tris(2,4-di-tert-butylphenyl) phosphite (AO168) used in combination with AO1010 displays synergistic properties promoting melt processing and longer term stability. ${ }^{[6]}$

Despite the significance of polyolefin additives in commercial applications, their properties and interactions, particularly with nucleators, remain poorly understood. ${ }^{[6]}$ The efficiency of DBP-based clarifiers is largely dependent on their self-assembly properties, which in turn is determined by their chemical structure. Small changes in the composition and structure of the clarifier molecules have been shown to significantly affect the fibrils formation. ${ }^{[18]}$ Jana and co-workers reported that interactions between sorbitols and silanol groups of polyhedral oligomeric silsequioxane (POSS) molecules could hinder fibrils formation in PP, particularly when a combination of hydrogen-bonding and $\pi-\pi$ interactions is at play. ${ }^{[19,20]}$ The common use of polymer additive blends to facilitate handling and dosing of multiple polymer additives require a better understanding of their synergistic and antagonistic interactions. Furthermore, the preparation of polymer additive blends in powder form, cold compacted form, or melt blends involve differences in thermal history and intimacy of mixing of the additives. ${ }^{[21]}$

We studied the interactions between TBPMN and common PP additives, and showed that the thermal stability and nucleation efficiency of the mixtures are dependent on their composition and processing history. The thermal behavior of the mixtures was investigated by thermogravimetric analysis (TGA), and differential scanning calorimetry (DSC). Fourier-transform infrared (FTIR) spectroscopy probed the modification of the chemical structures. Optical microscopy was employed to determine the self-assembly properties of the nucleator, and influence of additives. Finally, the crystallization temperature was used as a measure of nucleator performance in polymer blends prepared by internal mixing.

\section{2 | EXPERIMENTAL CONDITIONS}

\section{1 | Materials}

1,2,3-trideoxy-4,6:5,7-bis-O-[(4-propylphenyl)methylene]nonitol (TBPMN) (Millad NX8000), was obtained from Milliken, and dried in a vacuum oven at $60^{\circ} \mathrm{C}$ for 12 hours prior to use. Calcium distearate (CaSt) was obtained from Baerlocher (Ceasit FI Veg), and Mg-Al hydrotalcite (DHT) was provided by Kyowa Chemical Industry. Glycerol monostearate (GMS) was purchased from Riken (Rikemal AS-005). Pentaerythritol tetrakis(3-[3,5-di-tert-butyl4-hydroxyphenyl]propionate) (AO1010, Evernox-10) and tris(2,4-di-tert-butylphenyl) phosphite (AO168, Everfos168) were purchased from Everspring Chemical. Isotactic polypropylene (PP 526P, melt flow rate at $230^{\circ} \mathrm{C}$ and $2.16 \mathrm{~kg}: 8 \mathrm{~g} / 10$ minutes, density: $905 \mathrm{~kg} / \mathrm{m}^{3}$ ) was provided by Sabic.

\section{2 | Characterization techniques}

TGA was performed on a TA Instruments TGA 550 equipped with an autosampler, under $\mathrm{N}_{2}$ or air 
atmosphere. Approximately 3 to $10 \mathrm{mg}$ of sample was used for each measurement. The temperature was equilibrated for 1 minute at $30^{\circ} \mathrm{C}$, and increased to $650^{\circ} \mathrm{C}$ at a rate of $10^{\circ} \mathrm{C} / \mathrm{min}$. The differential thermogravimetric curves were calculated with the software TRIOS (TA Instruments), and with application of a moving average smoothing function.

DSC was performed with a Perkin Elmer Pyris 1 equipped with liquid nitrogen cooling. Aluminum pans were sealed under air with ca. $5 \mathrm{mg}$ of sample for the powder blends and ca. $10 \mathrm{mg}$ for the PP blends. The measurement with TBPMN under nitrogen was performed with a pan sealed in a glove box under nitrogen atmosphere. Scans were performed at $10^{\circ} \mathrm{C} / \mathrm{min}$, measuring two successive cycles, each cycle consisting in heating the sample from $20^{\circ} \mathrm{C}$ to $260^{\circ} \mathrm{C}$, keeping the temperature at $260^{\circ} \mathrm{C}$ for 5 minutes, and cooling to $20^{\circ} \mathrm{C}$. Measurements of PP blends were performed with similar thermal cycles, but with a maximum temperature of $200^{\circ} \mathrm{C}$.

The chemical composition was characterized by FTIR spectroscopy with a Bruker ALPHA equipped with a platinum single reflection diamond ATR QuickSnap sampling module.

The self-assembled structure of TBPMN was studied with a hot stage (Linkam T-95) and imaged with a polarized light optical microscope (PLOM, Olympus BX60F-3). The sample was first deposited on a glass slide and placed under a cover slip. The measurements were done under nitrogen or air flow. The thermal cycles were as follows: the sample was heated from $25^{\circ} \mathrm{C}$ to the melting temperature $\left(T_{\mathrm{m}}\right)$, kept at $T_{\mathrm{m}}$ for 5 minutes, and cooled to $25^{\circ} \mathrm{C}$. The heating and cooling rates were $10^{\circ} \mathrm{C} / \mathrm{min}$.

Formulated polypropylene was prepared by first drymixing the additive powders and polymer pellets, followed by addition to a Plasti-Corder Lab-Station Brabender internal mixer, operating at $220^{\circ} \mathrm{C}$ for 5 minutes at $35 \mathrm{rpm}$. Alternately, a melt-formed polymer additive pre-blend (Superblend Type D, Ingenia Polymers) was prepared by dry extrusion of the nucleator and polymer additives at $800 \mathrm{rpm}$ using a Krauss Maffei ZE 25 twin-screw extruder. The extrusion temperature used was $85^{\circ} \mathrm{C}$ for TBPMN/ GMS $(1 / 1 \mathrm{w} / \mathrm{w})$ [Type D1], $135^{\circ} \mathrm{C}$ for TBPMN/AO1010 $(4 / 1 \mathrm{w} / \mathrm{w})$ [Type D2], $185^{\circ} \mathrm{C}$ for TBPMN/AO168/AO1010 (4/2/1) [Type D3], and $115^{\circ} \mathrm{C}$ for all the other formulations. The Type D additive pre-blend was then blended with polymer pellets, followed by addition to a Plasti-corder LabStation Brabender under identical conditions to the powder blends. Mixtures were prepared according to a representative PP formulation containing the following weight ratio of additives: TBPMN/GMS/CaSt/AO168/AO1010 4/1/1/1/1 or otherwise indicated.

A list of all samples, with their composition and analysis performed is reported in Table S1, in the supporting information.

\section{3 | RESULTS AND DISCUSSION}

\section{1 | Thermal stability}

The chemical structures of the nucleator and selected additives are shown in Figure 1. The thermal stability of each compound was determined by TGA under inert atmosphere (Table 1, and Figure S1). TBPMN displayed a high thermal stability, with an extrapolated onset degradation temperature $\left(T_{\mathrm{o}}\right)$ of $278^{\circ} \mathrm{C}$ and maximum rate of decomposition temperature $\left(T_{\mathrm{p}}\right)$ of $311^{\circ} \mathrm{C}$. The linear degradation rate under isothermal condition at $250^{\circ} \mathrm{C}$ was $0.83 \mathrm{wt} \% / \mathrm{min}$ (not shown). Measurements performed under air decreased $T_{\mathrm{o}}$ to $228^{\circ} \mathrm{C}$, highlighting the susceptibility of the nucleator to oxidative degradation. In order to exclude the effect of oxidation, all further TGA measurements were carried under inert atmosphere.

Both GMS and AO168 pyrolyzed at a lower temperature than the clarifier, while CaSt and AO1010 displayed a $T_{\mathrm{o}}$ above $369^{\circ} \mathrm{C}$ (Table 1, Figure S1). It is noteworthy that GMS exhibited two decomposition temperatures at $240^{\circ} \mathrm{C}$ and $360^{\circ} \mathrm{C}$. Commercial GMS samples are commonly constituted of mixtures of mono-, di-, and tri-ester glycerol compounds, with alkyl chain derivatives of stearic and palmitic acids. ${ }^{[17,22]}$ The latter fatty acids have a marked difference in decomposition temperatures, ca. $327^{\circ} \mathrm{C}$ and $261^{\circ} \mathrm{C}$, respectively. ${ }^{[23,24]}$ The higher molar mass compounds assigned to glycerol monosterate accounted for $46 \mathrm{wt} \%$ of the GMS additive. CaSt was constituted of $1 \mathrm{M}$ equivalent (3 wt\%) of water of crystallization, which was removed around $100^{\circ} \mathrm{C}$ (Figure S1). ${ }^{[16]}$

Blending TBPMN with the fatty acid-based compounds lowered the thermal stability of the clarifier (Table 1, Figure S2). Accounting for the loss of GMS, the onset degradation of TBPMN/GMS $(4 / 1 \mathrm{w} / \mathrm{w})$ was $233^{\circ} \mathrm{C}$ (Figure S4a). $T_{\mathrm{o}}$ of TBPMN was decreased by $30^{\circ} \mathrm{C}$ in presence of CaSt (Figure $\mathrm{S} 4 \mathrm{~b}$ ). These temperatures represent, therefore, an upper limit for the processing window of nucleator/additives blends. A mixture of TBPMN with both GMS and CaSt displayed a thermal stability slightly higher than that of mixtures prepared with only one additive, suggesting synergistic interactions between the components (Table 1).

Inversely, blending of one antioxidant (AO1010 or A0168) with the clarifier resulted in an improvement in the overall thermal stability (Table 1, Figure S2). When both antioxidants were combined, $T_{\mathrm{O}}$ decreased slightly; but notably, a fraction of the sample remained stable up to $378^{\circ} \mathrm{C}$ (Figure S4c). The thermal stability of mixtures prepared with all four additives remained the same when the antioxidants were removed. This observation suggests a greater contribution of the GMS and CaSt on the change in thermal stability (Figure S3). 


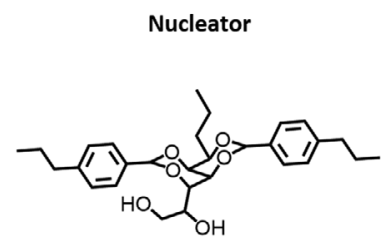

1,2,3-trideoxy-4,6:5,7-bis-0[(4-propylphenyl)methylene]-nonito (TBPMN) (Millad"NX8000)
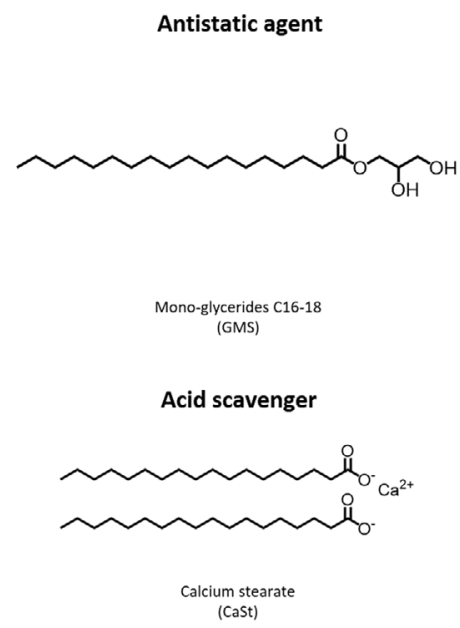

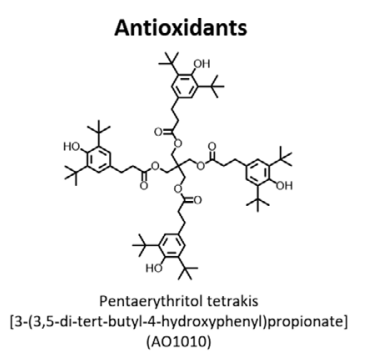

FIGURE 1 Chemical structures of the nucleator and additives

TABLE 1 Thermal analysis of the nucleator, additives, and powder blends

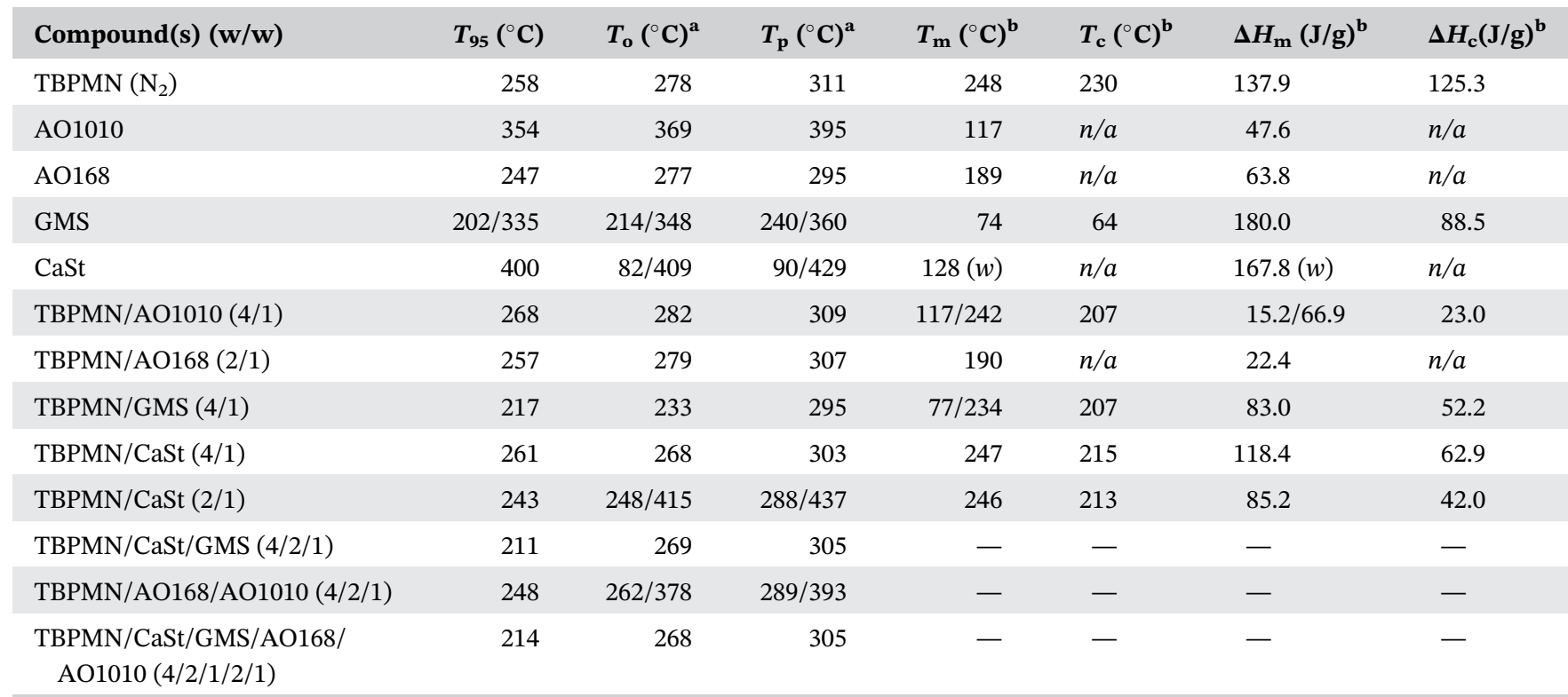

Note: $T_{\mathrm{o}}$, extrapolated onset degradation temperature; $T_{95}$, temperature at $5 \%$ mass loss; $T_{\mathrm{p}}$, maximum rate of decomposition temperature; $T_{\mathrm{m}}$, melting temperature; $T_{\mathrm{c}}$, crystallization temperature; $\Delta H_{\mathrm{m}}$, enthalpy of melting; $\Delta H_{\mathrm{c}}$, enthalpy of crystallization; $n / a$, non-applicable; $w$, evaporation of water and liquid crystal phase.

${ }^{\text {a }}$ Measured by thermogravimetric analysis at $10^{\circ} \mathrm{C} / \mathrm{min}$ under nitrogen.

${ }^{\mathrm{b}}$ Measured by differential scanning calorimetry at $10^{\circ} \mathrm{C} / \mathrm{min}$ in air or otherwise stated.

The lower thermal stability of GMS is expected to yield reactive species that can hydrolyze the nonitol clarifier. No change in composition was evident from FTIR analysis after heating TBPMN to $200^{\circ} \mathrm{C}$ (Figure S5). However, TBPMN/GMS powder blends showed evidence of an oxidative degradation mechanism upon heating, with appearance of a broad peak in the region 3300 to $3600 \mathrm{~cm}^{-1}$, assigned to $-\mathrm{OH}$ stretching vibration modes, at $1731 \mathrm{~cm}^{-1}(\nu \mathrm{C}=\mathrm{O})$, and at $1270 \mathrm{~cm}^{-1}$ and $1197 \mathrm{~cm}^{-1}(\nu \mathrm{C}-\mathrm{O})$ suggesting decomposition to fatty acids and alcohols (Figure 2). Sorbitols compounds are highly susceptible to hydrolysis under acidic environments and high temperature. ${ }^{[25]}$ FTIR analysis of the TBPMN/CaSt mixture heated to $200^{\circ} \mathrm{C}$ revealed peaks at $1720 \mathrm{~cm}^{-1}$, assigned $\mathrm{C}=\mathrm{O}$ stretching modes, $1548 \mathrm{~cm}^{-1}\left(\nu \mathrm{COO}^{-}\right)$and peak broadening at $1551 \mathrm{~cm}^{-1}$ (Figure S6). After heating mixtures with GMS or CaSt, a lower IR absorbance was noted in the 1200 to $460 \mathrm{~cm}^{-1}$ region, which was attributed to $\mathrm{C}-\mathrm{C}$ stretching and bending modes, and $\mathrm{CH}_{3}$ rocking modes. This data further suggests degradation of the aliphatic chains taking place. 


\section{2 | Crystallization of the sorbitol-type nucleator}

Further investigation on the thermal stability of the clarifier and powder blends was carried out by DSC. As shown in Figure 3, under inert atmosphere TBPMN displayed a sharp melting peak at $248.0^{\circ} \mathrm{C}$. The deleterious effect of oxygen was apparent from comparable measurements performed under air. The melting range decreased by about $5^{\circ} \mathrm{C}$ and broadened, and an exothermic event associated to thermal degradation appeared above $199.1^{\circ} \mathrm{C}$. Degradation of the clarifier was already noted above $228^{\circ} \mathrm{C}$ from TGA measurements.

Upon cooling, recrystallization of the clarifier under inert atmosphere occurred below $231.0^{\circ} \mathrm{C}$, with only a small decrease in the enthalpy (Figure 4, and Table 1).

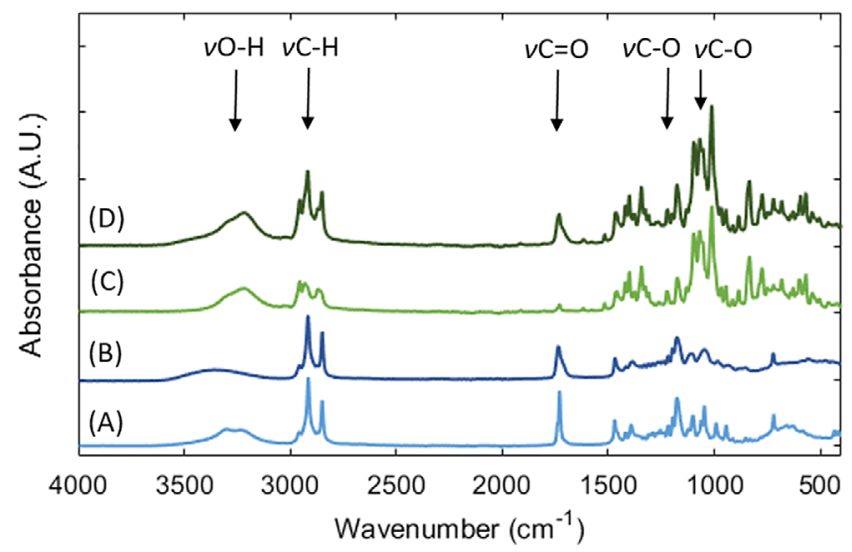

F I G U R E 2 FTIR analysis of GMS at A, room temperature and $\mathrm{B}$, after thermal treatment at $200^{\circ} \mathrm{C}$, and of TBPMN/GMS (4/1 $\mathrm{w} / \mathrm{w}$ ) powder blends at $\mathrm{C}$, room temperature and $\mathrm{D}$, after thermal treatment at $230^{\circ} \mathrm{C}$ [Color figure can be viewed at wileyonlinelibrary.com]

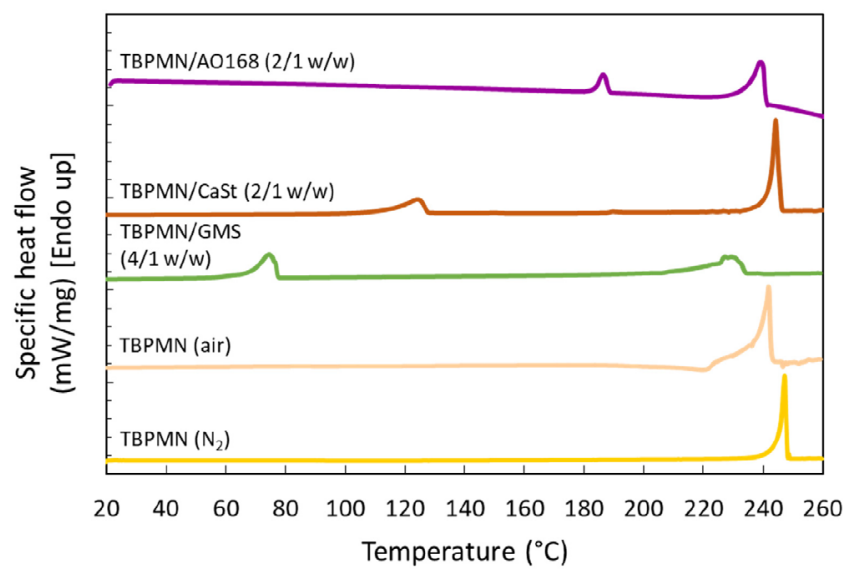

F I G U RE 3 Differential scanning calorimetry melting curves of TBPMN and corresponding powder blends [Color figure can be viewed at wileyonlinelibrary.com]
From the same measurement performed under air, only small exothermic peaks were apparent below $173.9^{\circ} \mathrm{C}$, revealing the inability of the oxidized clarifier to recrystallize. This was confirmed by optical microscopy, and no fibrils were formed upon cooling of TBPMN from the melt. Since the efficiency of the nucleator is dependent on its self-assembly properties, it is expected that oxidation will deactivate the clarifier, as further discussed below.

The addition of GMS to the clarifier resulted in a broadening of the melting range, as shown in Figure 3. GMS melted above $74.4^{\circ} \mathrm{C}$ and a melting point depression of TBPMN occured above $199^{\circ} \mathrm{C}$, as evidenced by the two endothermic peaks. A colligative effect may account for the lower melting point. However, evidence for the oxidation of GMS upon heating, from FTIR analysis, suggests formation of lower molar-mass species such as fatty acids that may further react with TBPMN. Noteworthy, upon cooling a sharp recrystallization peak was still present, comparable to the crystallization peak of TBPMN in absence of oxygen but at a lower temperature and with a lower enthalpy of crystallization (Figure 4). This result suggests that GMS or its partial oxidative degradation could act as a barrier against the oxidation of the clarifier, but interfered with the recrystallization of the molecules. The ability of the nucleator to form fibrils was further characterized by optical microscopy and discussed below (Figure 6).

The thermal behavior for powder blends of the clarifier and CaSt is shown in Figures 3 and 4. Separation of the water of crystallization and loss of the CaSt crystalline structure occurred around $125^{\circ} \mathrm{C}$. Above this temperature, CaSt has been reported to form a viscous melt. ${ }^{[16]}$ A sharp melting peak for the blend was measured at $246.4^{\circ} \mathrm{C}$, but recrystallization of TBPMN occurred at a

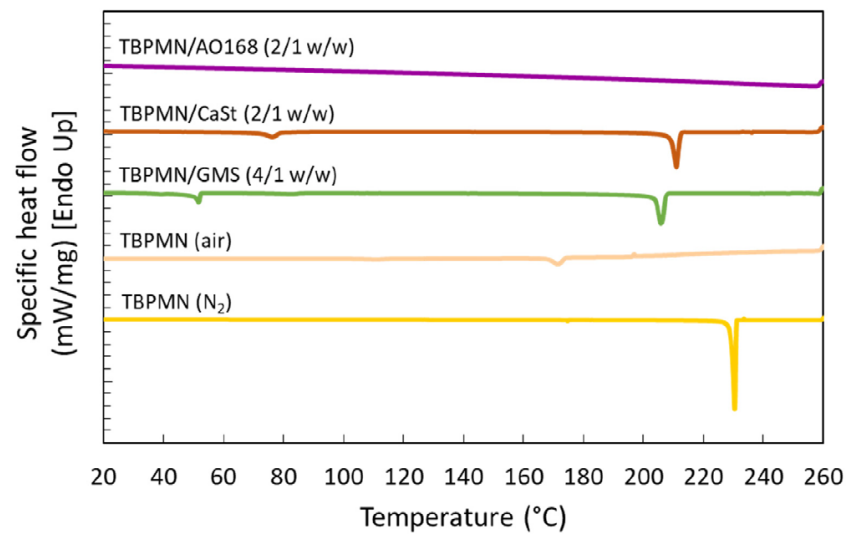

F I G U RE 4 Differential scanning calorimetry cooling curves of TBPMN and corresponding powder blends [Color figure can be viewed at wileyonlinelibrary.com] 
lower temperature. In addition, a slightly lower enthalpy of crystallization suggests a lower efficiency for CaSt to protect the clarifier against oxidation. A lower amount of CaSt $(4 / 1 \mathrm{w} / \mathrm{w})$ proved more effective at protecting the nucleator from oxidation (Table 1). TGA data revealed that the thermal degradation temperature of TBPMN/ CaSt blend is close to CaSt melting point. In comparison to the effect of GMS, the metal stearate or its oxidative degradation may help protect the nucleator from further oxidation.

DSC analysis of AO168 under air indicated no change in the enthalpy of fusion after heating to $220^{\circ} \mathrm{C}$, suggesting good thermal stability and recrystallization of the compound. However, under the same conditions no further melting peak was present after a first heating cycle for AO1010 (not shown). This is an indication of the amorphous structure of the compound after melting. ${ }^{[26]}$ Mixtures of TBPMN/AO168 proved sensitive to thermal treatment, and no crystallization peak occurred upon cooling (Figures 3 and 4); while TBPMN/AO1010 mixtures displayed a crystallization peak at $207^{\circ} \mathrm{C}$.

\section{3 | Self-assembly of the sorbitol-type nucleator}

The performance of sorbitol-type clarifiers is closely associated to their molecular structure and ability to form a self-assembled fibrillar network in PP. This unique property has been attributed to the butterfly-shaped structure, constituted of a polar polyol core and non-polar aromatic "wings" (Figure 1). ${ }^{[3,8]}$ Favorable interactions with the phenyl rings promote solubility and homogeneous dispersion in non-polar media. Furthermore, noncovalent interactions between the molecules govern a one-dimensional fibrillar assembly. Several models have been proposed to account for the supramolecular formation, but a complete understanding remains elusive. Both hydrogen bonding with the hydroxyl groups and $\pi-\pi$ interactions between the aromatic rings have been shown to participate in the self-organization process. ${ }^{[27-30]}$ The fibril formation in the polymer melt or in solvents has been the subject of several studies. ${ }^{[5,31]}$ Selfassembled DBS fibrils from the melt have been shown to organize in spherulitic morphologies. ${ }^{[32,33]}$ To our knowledge however the self-assembly process of neat TBPMN upon cooling has not been monitored directly. ${ }^{[32,34]}$

As shown in Figure 5, after melting TBPMN at $240^{\circ} \mathrm{C}$ under $\mathrm{N}_{2}$ atmosphere, the self-assembly of the compound was monitored by optical microscopy under inert atmosphere. Upon cooling to $230^{\circ} \mathrm{C}$, the TBPMN droplets rapidly formed elongated structures over $300 \mu \mathrm{m}$ in length and less than $5 \mu \mathrm{m}$ in diameter. Noteworthy, upon similar thermal treatment under air, no fibril formed, indicative of the thermal oxidative degradation occurring at elevated temperatures.

The influence of each additive on the self-assembly process was determined from powder blends. In presence
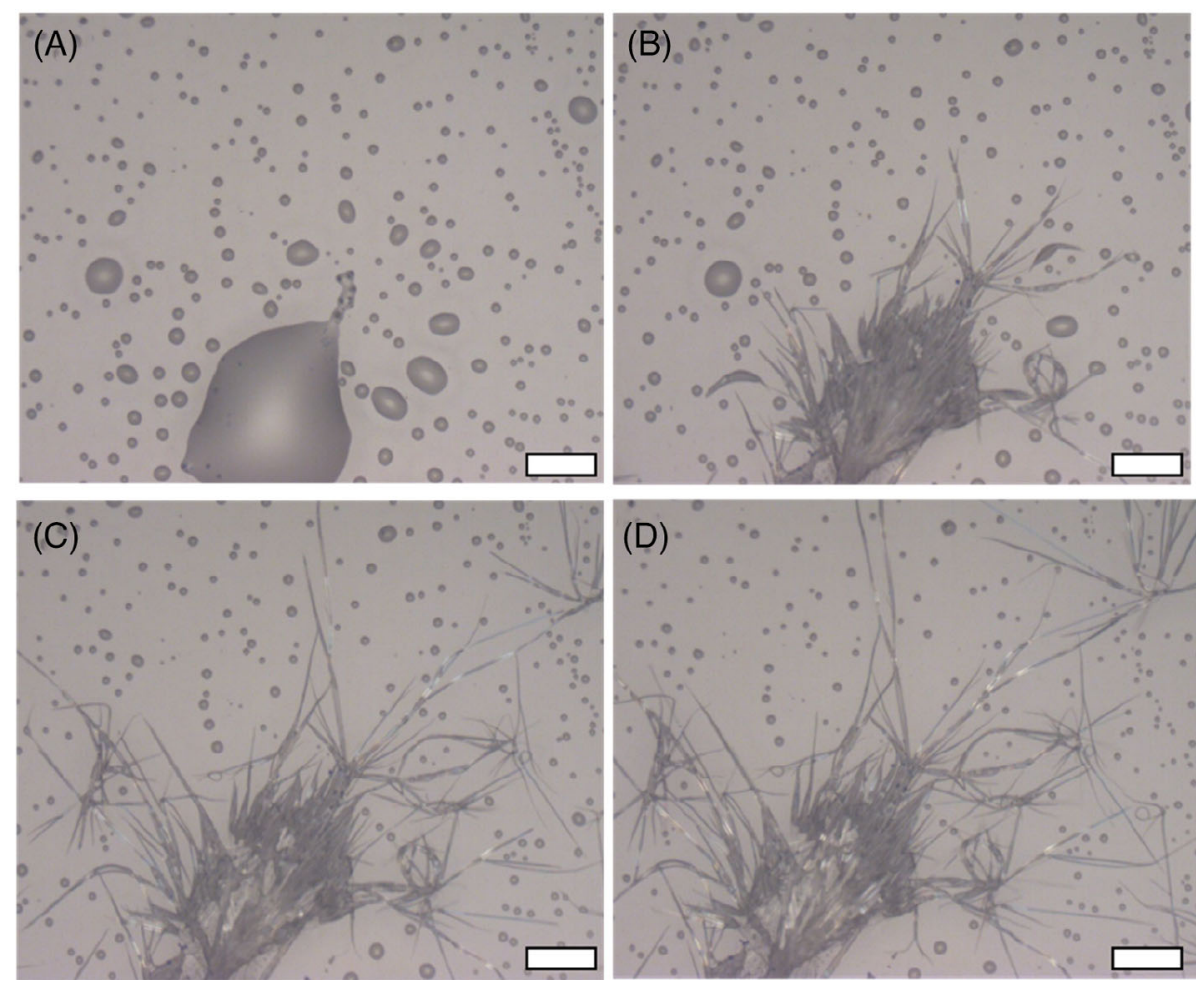

FIG URE 5 Optical micrographs of TBPMN at $\mathrm{A}, 240^{\circ} \mathrm{C}$, and after cooling to $\mathrm{B}, 230^{\circ} \mathrm{C}, \mathrm{C}, 230^{\circ} \mathrm{C}$ for 30 seconds, and $\mathrm{D}, 230^{\circ} \mathrm{C}$ for 2 minutes. Scale bars represent $50 \mu \mathrm{m}$ [Color figure can be viewed at wileyonlinelibrary.com] 
of GMS, a dense network of thin fibrils formed upon cooling (Figure 6A and B). Much shorter fibrils, about $40 \mu \mathrm{m}$ in length, were obtained. The liquid GMS may promote greater dispersion of the clarifier and formation of thinner fibrils into a dense network. In presence of CaSt, micellar structures were rather observed at $240^{\circ} \mathrm{C}$. Upon cooling, fibril formation took place, but the network was restricted to the dense micellar aggregates (Figure 6C and D). Optical micrographs of the powder blends between TBPMN and AO168 (or AO1010) indicated the formation of fibrillar structures comparable in size to fibrils formed in PP (Figure 7). However, aggregation into micellar structures was also observed suggesting the formation of surface-active species that partially hindered the self-assembly process.

\section{4 | Nucleator performance}

The nucleator performance of TBPMN was evaluated by measuring the crystallization temperature $\left(T_{\mathrm{c}}\right)$ of isotactic PP blends processed at $220^{\circ} \mathrm{C}$. An increase in $T_{\mathrm{c}}$ has been
F I G U RE 6 Optical micrographs of TBPMN/GMS (4/1) powder blend A, at $20^{\circ} \mathrm{C}$, and $\mathrm{B}$, at $80^{\circ} \mathrm{C}$ after cooling from melt; and of TBPMN/CaSt $(2 / 1 \mathrm{w} / \mathrm{w})$ powder blend $\mathrm{C}$, at $20^{\circ} \mathrm{C}$, and $\mathrm{D}$, at $80^{\circ} \mathrm{C}$ after cooling from melt. Scale bars represent $50 \mu \mathrm{m}$ [Color figure can be viewed at wileyonlinelibrary.com]

FI G URE 7 Optical micrographs of TBPMN/AO168 (2/1 w/w) powder blend $\mathrm{A}$, at $20^{\circ} \mathrm{C}$ and $\mathrm{B}$, at $80^{\circ} \mathrm{C}$ after cooling from melt; and of TBPMN/ AO1010 (4/1 w/w) powder blend $\mathrm{C}$, at $20^{\circ} \mathrm{C}$ and $\mathrm{D}$, at $80^{\circ} \mathrm{C}$ after cooling from melt. Scale bars represent $50 \mu \mathrm{m}$ [Color figure can be viewed at wileyonlinelibrary.com]
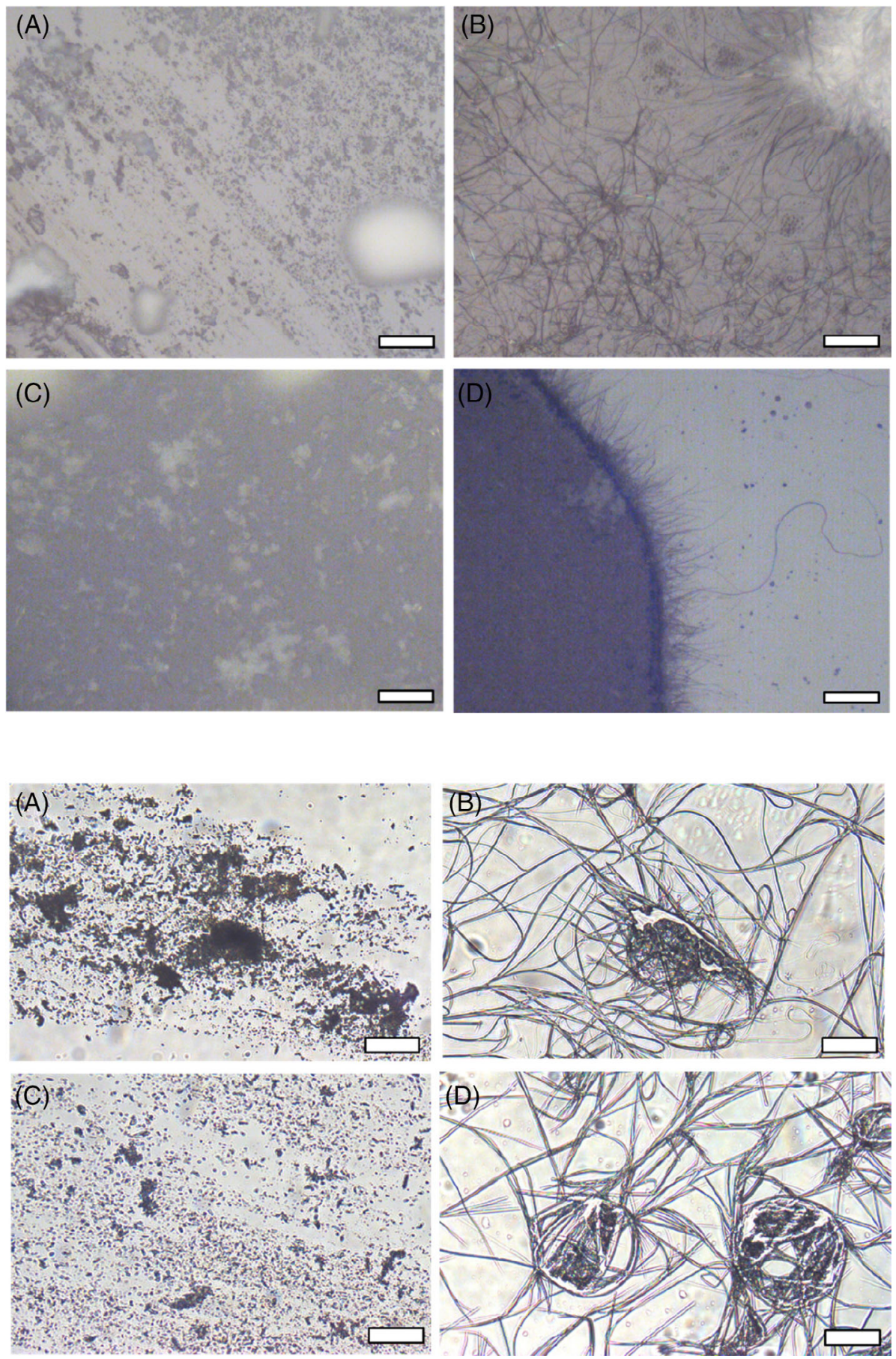
quantitatively associated to an improvement in the clarifying properties of sorbitol compounds. ${ }^{[35]}$ TBPMN was already shown to dissolve in PP melt, and to form a fibrillar network upon cooling (Figure S7). Above a critical concentration, a sharp increase in $T_{\mathrm{c}}$ is associated with network formation and epitaxial interaction with the polymer chains. ${ }^{[36]}$

As shown in Figure 8, $T_{\mathrm{c}}$ increased rapidly when the concentration of TBPMN was above $1000 \mathrm{ppm}$ and reached a plateau above $2000 \mathrm{ppm}$. The blends prepared with TBPMN/GMS $(2 / 1 \mathrm{w} / \mathrm{w})$ displayed a comparable trend, but with a higher $T_{\mathrm{c}}$ above $1500 \mathrm{ppm}$. As shown above, although GMS impacted the melting behavior of the clarifier, it may provide protection against oxidation or promote dispersion of the clarifier during melt.

CaSt resulted in the significant deactivation of the nucleator at $2000 \mathrm{ppm}$. As already observed by optical microscopy, the fibrils growth was hindered in presence of CaSt, and FTIR measurements suggested interaction with clarifier molecules. The self-assembly of TBPMN is driven by a balance between the H-bonding contribution of the hydroxyl groups and the $\pi-\pi$ interactions of the aromatic rings. ${ }^{[27]}$ Carboxylic acid species would therefore be susceptible to $\mathrm{H}$-bonding with TBPMN and hinder the self-assembly process. In addition, CaSt was shown to be detrimental to PP during processing by promoting oxidative degradation. ${ }^{[37]}$

Antioxidants proved the most beneficial to the nucleation efficiency, and $T_{\mathrm{c}}$ reached $128.4^{\circ} \mathrm{C}$ at $2000 \mathrm{ppm}$. This is further indication of the need to protect the clarifier from oxidation during processing for optimizing the performance.

\section{5 | Processing conditions}

The processing conditions were of importance when mixing nucleators and additives. GMS and AO1010 were

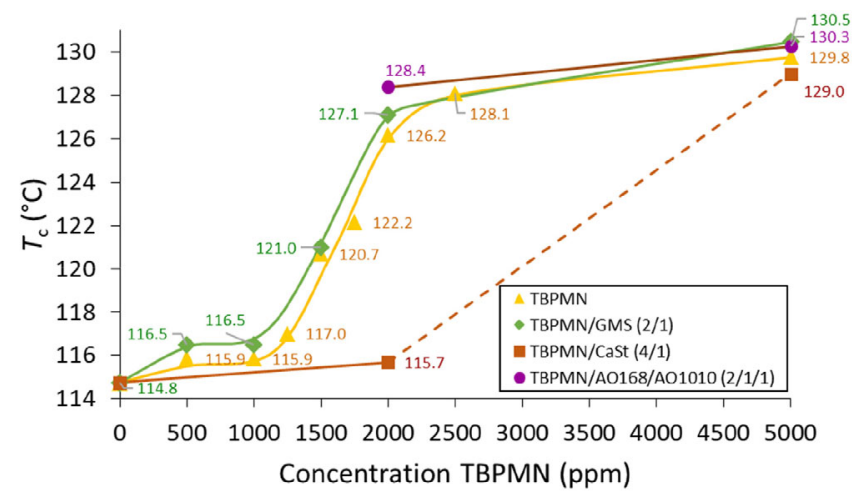

F I G U R E 8 Crystallization temperatures $\left(T_{\mathrm{c}}\right)$ for PP letdowns after direct powder addition of additives to $\mathrm{PP}$, and processed with various concentrations of TBPMN at $220^{\circ} \mathrm{C}$ [Color figure can be viewed at wileyonlinelibrary.com] pre-blended with the nucleator (Type D1 and D2, respectively) at relatively low temperatures and with nitrogen blanketing the feed throat of the extruder to minimize thermal degradation. However, the nucleation efficiency of these pre-blends was lower than for formulations prepared from powders (Figure 9). Although both GMS and AO1010 were found to promote dispersion and minimize oxidation, interactions during processing lowered the nucleation efficiency of TBPMN. When both antioxidants were combined (Type D3), a good performance was obtained comparable to that of the nucleator alone. This suggests that the synergistic contribution of the

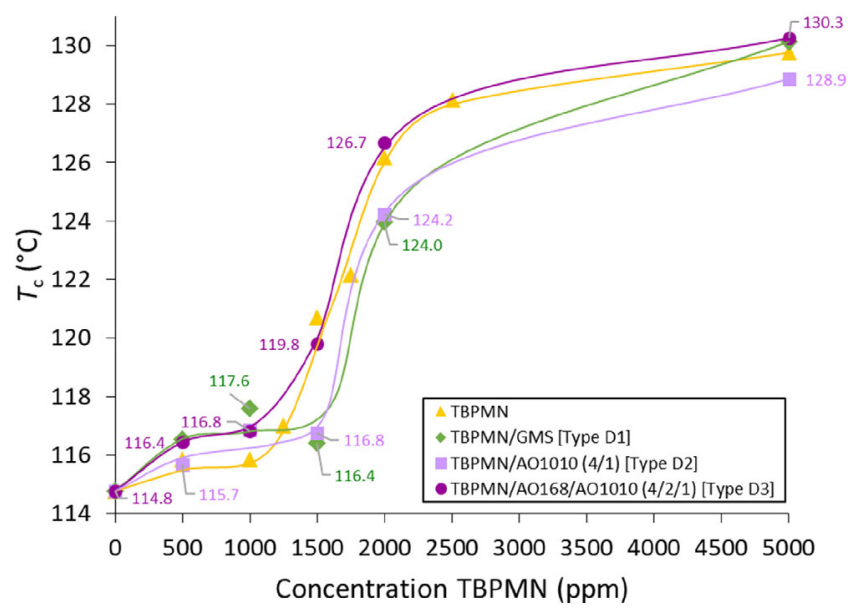

F I G U RE 9 Crystallization temperature $\left(T_{\mathrm{c}}\right)$ for PP letdowns with various concentrations of TBPMN, and with additives first processed into pre-blends by extrusion (Type D) [Color figure can be viewed at wileyonlinelibrary.com]

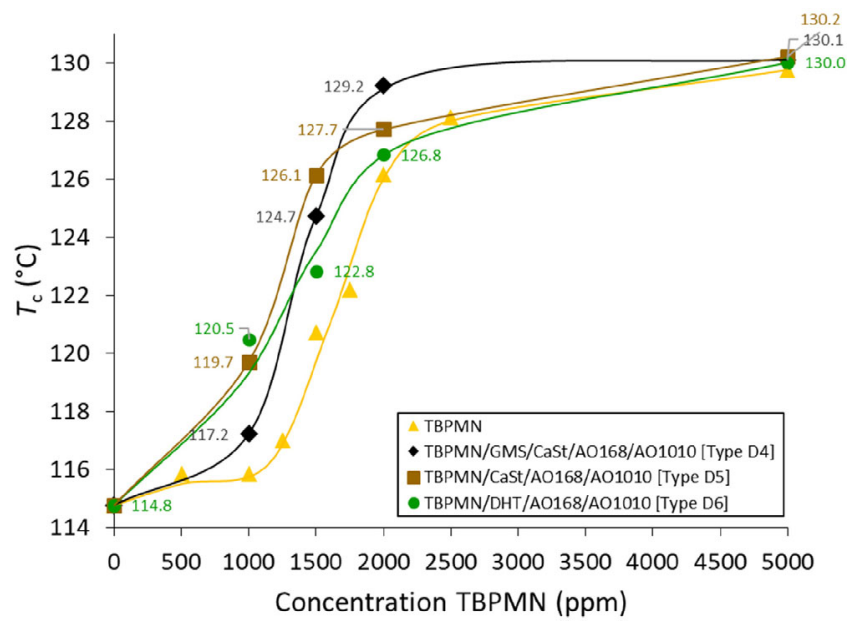

F I G U RE 10 Crystallization temperature $\left(T_{\mathrm{c}}\right)$ for PP letdowns with various concentrations of TBPMN, and with additives first processed into pre-blends by extrusion (Type D) [Color figure can be viewed at wileyonlinelibrary.com] 
antioxidants or their larger amount helped prevent nucleator deactivation.

The highest nucleation performance was obtained from pre-blends containing all the additives, with a $T_{\mathrm{c}}$ of $129.2^{\circ} \mathrm{C}$ with $2000 \mathrm{ppm}$ of TBPMN (Type D4, Figure 10). This supports the previous hypothesis that the nucleator benefits from protection against oxidation from the antioxidants, and dispersion of the nucleator and additives in PP is favored by the presence of lubricating compounds (Type D5). This processing method was also effective to a lower extend with other acid scavenger additives, such as, hydrotalcite (Type D6).

\section{4 | CONCLUSIONS}

We studied the interactions between the clarifying agent TBPMN, and four additives, namely; CaSt, GMS, AO1010, and AO168. TBPMN displayed good thermal stability but was susceptible to oxidative degradation under air, which was detrimental to its nucleation efficiency. In presence of GMS or CaSt, the thermal stability was slightly lowered, but the dry powder pre-blends proved beneficial to protect TBPMN against further oxidation. GMS was found to dissociate into fatty acids at elevated temperatures while CaSt yielded carbonyl adducts. The self-assembly process from melted TBPMN was monitored by optical microscopy and revealed formation of long fibrils. Fibrils formation was hindered under oxygen atmosphere but took place with all the additives under inert atmosphere. GMS promoted dispersion of the TBPMN and formation of a dense network of thin fibrils. CaSt rather resulted in micellar aggregated structures. Aggregates were also noted with the AOs but long fibrillar structures still formed.

When combined with PP, powder blends of the nucleator and GMS displayed enhanced nucleation efficiency. Protection from oxidation and improved dispersion in PP may account for the synergistic properties observed. CaSt was less effective and rather lowered the crystallization temperature of the nucleator. The use of antioxidants with the nucleator was beneficial and improved the nucleation performance, although DSC curves showed an inhibition of the crystallization of the nucleator at high concentration. Pre-melt processing of the additives, as a Type D Superblend, prior to their addition to the polymer proved a suitable route, provided that both antioxidants are present. This study paves the way to the rational design of effective processing methods to incorporate both nucleator and polymer additives to polypropylene and enhance the clarifier performance.

\section{ORCID}

O.J. Nguon (1) https://orcid.org/0000-0002-4124-2810

G.J. Vancso (1) https://orcid.org/0000-0003-4718-0507

\section{REFERENCES}

[1] Reports and Data Polypropylene Market by Type, by Grade, by Molding Techniques, by Application, by End-Users (Automotive, Packaging, Construction, Electrical \& Electronics Consumer Goods, and Others), and Segment Forecasts. 2019.

[2] R. Lieberman, in Encyclopedia of Polymer Science and Technology, Vol. 11 (Ed: H. F. Mark), Wiley-Interscience, New York, NY 2004, p. 287.

[3] A. Thierry, B. Fillon, C. Straupé, B. Lotz, J. C. Wittmann, Prog. Colloid Polym. Sci. 1992, 87, 28.

[4] F. Horváth, J. Molnár, Alfréd, M. in Polypropylene Handbook (Eds: J. Karger-Kocsis, T. Bárány), Springer, Cham 2019, p. 121.

[5] B. O. Okesola, V. M. P. Vieira, D. J. Cornwell, N. K. Whitelaw, D. K. Smith, Soft Matter 2015, 11(24), 4768.

[6] M. Tolinski Ed., Additives for Polyolefins, 2nd, William Andrew, Oxford, UK 2015.

[7] M. Gahleitner, C. Grein, S. Kheirandish, J. Wolfschwenger, Int. Polym. Process. 2011, 26(1), 2.

[8] A. Thierry, C. Straupé, B. Lotz, J. C. Wittmann, Polym. Commun. 1990, 31(8), 299.

[9] M. Kristiansen, M. Werner, T. Tervoort, P. Smith, M. Blomenhofer, H. W. Schmidt, Macromolecules 2003, 36(14), 5150.

[10] M. Tenma, N. Mieda, S. Takamatsu, M. Yamaguchi, J. Polym. Sci. Part B Polym. Phys. 2008, 46(1), 41.

[11] Z. Horváth, B. Gyarmati, A. Menyhárd, P. Doshev, M. Gahleitner, J. Varga, B. Pukánszky, RSC Adv. 2014, 4(38), 19737.

[12] S. Nagasawa, A. Fujimori, T. Masuko, M. Iguchi, Polymer 2005, 46(14), 5241.

[13] Xie, C.; Rieth, L. R.; Danielson, T. D. Dibenzylidene sorbitol (DBS)-based compounds, compositions and methods for using such compounds, US 7662978, 2010.

[14] K. Bernland, T. Tervoort, P. Smith, Polymer 2009, 50(11), 2460.

[15] D. Dieckmann, J. Vinyl Addit. Technol. 2001, 7(1), 51.

[16] Sherman, R. L.; Kern, K. E. In Handbook of Industrial Polyethylene Technology; Spalding, M. A., Chatterjee, A. M., Eds.; Scrivener: Beverly, MA, 2018; pp. 793-820.

[17] G. Butuc, G. Spijkerman, S. te Hofstee, T. Kampen, in Handbook of Industrial Polyethylene Technology (Eds: M. A. Spalding, A. M. Chatterjee), Scrivener, Beverly, MA 2018, p. 853.

[18] A. Singh, F. I. Auzanneau, M. G. Corradini, G. Grover, R. G. Weiss, M. A. Rogers, Langmuir 2017, 33(41), 10907.

[19] S. Roy, V. Scionti, S. C. Jana, C. Wesdemiotis, A. M. Pischera, M. P. Espe, Macromolecules 2011, 44(20), 8064.

[20] S. Roy, J. Feng, V. Scionti, S. C. Jana, C. Wesdemiotis, Polymer 2012, 53(8), 1711.

[21] S. d'Uva, Z. Charlton, ANTEC proceedings, Society of Plastics Engineers 2004, p. 2788.

[22] Nielsen, B. In Int. Conf. on Additives for Polyolefins; 1998; pp. 123-132.

[23] Y. Chen, X. Zhang, B. Wang, M. Lv, Y. Zhu, J. Gao, RSC Adv. 2017, 7(26), 15625.

[24] N. Agrawal, S. Munjal, M. Z. Ansari, N. Khare, Ceram. Int. 2017, 43(16), 14271.

[25] T. Schamper, M. Jablon, M. H. Randhawa, A. Senatore, J. D. Warren, J. Soc. Cosmet. Chem 1986, 37(4), 225. 
[26] Neri, C.; Nodari, N.; Sandre, G.. Tetrakis(3-[3,5-di-tert.buyl4-hydroxyphenyl]propionyl-oxymethyl) methane with amorphous structure, process for its preparation and its use as a stabilizer, US4886900A, 1989.

[27] J. Li, K. Fan, X. Guan, Y. Yu, J. Song, Langmuir 2014, 30(44), 13422.

[28] E. A. Wilder, R. J. Spontak, C. K. Hall, Mol. Phys. 2003, 101 (19), 3017.

[29] M. Watase, Y. Nakatani, H. Itagaki, J. Phys. Chem. B 1999, 103 (13), 2366.

[30] S. Yamasaki, Y. Ohashi, H. Tsutsumi, K. Tsujii, Bull. Chem. Soc. Jpn 1995, 68(1), 146.

[31] W. C. Lai, S. J. Tseng, P. H. Huang, J. Nanoparticle Res 2015, $17(11), 1$.

[32] D. J. Mercurio, R. J. Spontak, J. Phys. Chem. B 2001, 105(11), 2091.

[33] W.-C. Lai, C.-H. Wu, J. Appl. Polym. Sci. 2010, 115(2), 1113.

[34] S. Liu, W. Yu, C. Zhou, Soft Matter 2013, 9(3), 864.

[35] Z. Horváth, A. Menyhárd, P. Doshev, M. Gahleitner, G. Vörös, J. Varga, B. Pukánszky, ACS Appl. Mater. Interfaces 2014, 6(10), 7456.
[36] J. Lipp, M. Shuster, A. E. Terry, Y. Cohen, Langmuir 2006, 22 (14), 6398.

[37] C. A. Russell, Polym. Eng. Sci 1965, 5(2), 84.

\section{SUPPORTING INFORMATION}

Additional supporting information may be found online in the Supporting Information section at the end of this article.

How to cite this article: Nguon OJ, Charlton Z, Kumar M, Lefas J, Vancso GJ. Interactions between sorbitol-type nucleator and additives for polypropylene. Polym Eng Sci. 2020;1-10. https:// doi.org/10.1002/pen.25535 